\title{
Direct torque control of a doubly fed induction generator
}

\author{
A. Ben Amar ${ }^{1}$, S. Belkacem ${ }^{1}$, T. Mahni ${ }^{2}$ \\ ${ }^{I}$ Department of Electrical Engineering, University of Batna, ALGERA \\ ${ }^{2}$ LGEB Laboratories, Department of Electrical Engineering, University of Biskra, ALGERA \\ b.asma39@gmail.com
}

\begin{abstract}
In this paper a direct torque control system is proposed and is applied to doubly fed induction generator (DFIG) based wind power generation systems. In this control system the rotor flux and the electromagnetic torque are estimated based on the rotor voltage and currents measurements. The validity and effectiveness of this control is demonstrated by some simulation results.
\end{abstract}

Keywords: Doubly fed induction generator (DFIG), wind power generation systems, direct torque control (DTC), Field oriented control (FOC)

\section{Introduction}

Doubly fed induction generators (DFIGs) are used mainly for wind energy conversion in MW range. The stator is directly connected to grid while the rotor is fed through power electronic converter. The power electronic converter is rated at $25 \%$ to $30 \%$ of the generator rating for a variation in synchronous speed around $\pm 25 \%$. The major advantages of the DFIG based wind turbines are variable speed operation and stator power factor control from rotor side converter [1].

Direct torque control (DTC) was proposed in1980s and then it was well developed in power electronics and drives application for its excellent steady state and transient performance [2-3]. Compared to field oriented control (FOC) technique, DTC system is very simple and robust because current regulators and complicate coordinate transformation are eliminated [3].

Today Direct Torque Control (DTC) is considered one of the most important techniques to achieve high dynamic performance in AC machines. The direct torque control (DTC) scheme has been increased due to several factors such as quick torque response and robustness against the machine parameter variations [4].

In this paper the conventional DTC algorithm using the hysteresis based voltage switching method is applied to DFIG.

\section{Mathematical modeling of DFIG}

The mathematical model of the DFIG used in this paper is presented here using the d-q synchronous reference frame. The equations for the stator and rotor windings can be written as [5-6]:

$$
\left\{\begin{array}{l}
V_{d s}=R_{s} I_{d s}+\frac{d \varphi_{d s}}{d t}-\omega_{s} \varphi_{q s} \\
V_{q s}=R_{s} I_{q s}+\frac{d \varphi_{q s}}{d t}+\omega_{s} \varphi_{d s} \\
V_{d r}=R_{r} I_{d r}+\frac{d \varphi_{d r}}{d t}-\omega_{r} \varphi_{q r} \\
V_{q r}=R_{r} I_{q r}+\frac{d \varphi_{q r}}{d t}+\omega_{r} \varphi_{d r}
\end{array}\right.
$$

Where the rotor frequency $\omega_{\mathrm{r}}$ is given by:

$$
\omega_{r}=\omega_{s}-p \Omega
$$

$\mathrm{V}_{\mathrm{d}}, \mathrm{V}_{\mathrm{qs}}, \mathrm{V}_{\mathrm{dr}}, \mathrm{V}_{\mathrm{qr}}$ are the $\mathrm{d}$ and $\mathrm{q}$ axis of the stator and rotor voltages; $\mathrm{I}_{\mathrm{ds}}, \mathrm{I}_{\mathrm{qs}}, \mathrm{I}_{\mathrm{dr}}, \mathrm{I}_{\mathrm{qr}}$ are the $\mathrm{d}$ and qaxis of the stator and rotor currents; $\varphi_{\mathrm{ds}}, \varphi_{\mathrm{qs}}, \varphi_{\mathrm{dr}}, \varphi_{\mathrm{qr}}$ are the $\mathrm{d}$ and $\mathrm{q}$ axis of the stator and rotor fluxes; $\omega_{\mathrm{s}}$ is the angular velocity of the synchronously rotating reference frame; $\omega_{\mathrm{r}}$ is the rotor angular velocity; and $\mathrm{R}_{s}, \mathrm{R}_{\mathrm{r}}$ are the stator and rotor resistances.

The flux equations of the DFIG are:

$$
\left\{\begin{array}{l}
\varphi_{d s}=L_{s} I_{d s}+M I_{d r} \\
\varphi_{q s}=L_{s} I_{q s}+M I_{q r} \\
\varphi_{d r}=L_{r} I_{d r}+M I_{d s} \\
\varphi_{q r}=L_{r} I_{q r}+M I_{q s}
\end{array}\right.
$$

Where: $L_{s}, L_{r}$ and $M$ are the stator, rotor and mutual inductances, respectively.

The electromagnetic torque given by

$$
\mathrm{T}_{\mathrm{e}}=-\frac{3}{2} \mathrm{p} \frac{\mathrm{M}}{\mathrm{L}_{\mathrm{s}}}\left(\mathrm{I}_{\mathrm{qr}} \varphi_{\mathrm{ds}}-\mathrm{I}_{\mathrm{dr}} \varphi_{\mathrm{qs}}\right)
$$

$\mathrm{P}$ is DFIG pairs of poles number. 


\section{Direct Torque Control}

The Direct Torque Control (DTC) method is basically a performance enhanced scalar control method. The main features of DTC are direct control of flux and torque by estimators implying the consequent parameters identification [7]. sinusoidal stator flux and stator currents and high dynamic performance even transformations which are required in most of vector controlled drive implementation and absence of separate voltage modulation block which is required in vector controlled drives. The disadvantages of DTC are inherent torque and stator flux ripple and requirement for flux and torque

As shown in Fig. 1, the position of the rotor flux is divided into six sectors. There are also 8 voltage vectors which correspond to possible inverter states. These vectors are shown in Fig. 1. There are also six active vectors $V_{1}, V_{2}, \ldots$, $\mathrm{V}_{6}$ and two zero vectors $\mathrm{V}_{0}$ and $\mathrm{V}_{7}$.

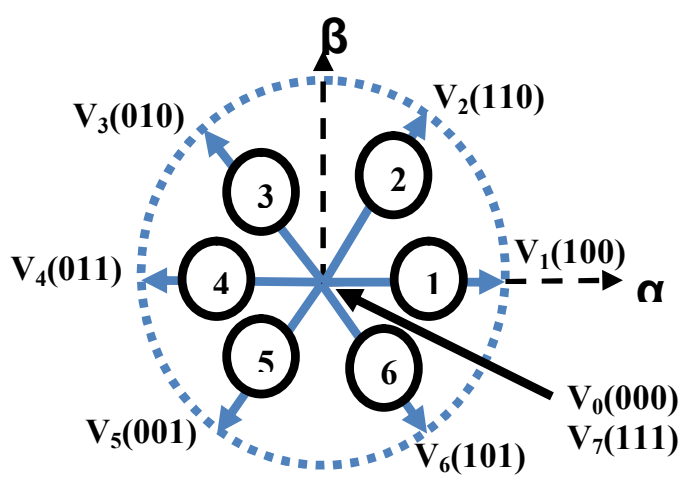

Figure. 1 Inverter output voltages

\section{A. Estimation of rotor flux}

The magnitude of the rotor flux is estimated from its components along the $\alpha$ and $\beta$ axes[8].

$\left\{\begin{array}{l}\varphi_{r \alpha}(t)=\int_{0}^{t}\left(V_{r \alpha}-R_{r} i_{r \alpha}\right) d t \\ \varphi_{r \beta}(t)=\int_{0}^{t}\left(V_{r \beta}-R_{r} i_{r \beta}\right) d t\end{array}\right.$

The amplitude of the rotor flux vector can be expressed by:

$\varphi_{r}=\sqrt{\varphi_{r \alpha}^{2}+\varphi_{r \beta}^{2}}(5)$

The angle $\alpha_{\mathrm{r}}$ of the rotor flux $\varphi_{\mathrm{r}}$ is determined by:

$\alpha_{r}=\operatorname{arctg} \frac{\varphi_{r \beta}}{\varphi_{r \alpha}}(6)$

\section{B. Estimation of the electromagnetic torque}

The electromagnetic torque can be estimated starting from the estimated value of the flux $\left(\varphi_{r \alpha}\right.$ and $\left.\varphi_{r \beta}\right)$ and the calculated values of the current $\left(i_{r \alpha}\right.$ and $\left.i_{r \beta}\right)$ [8]:

$$
\mathbf{T}_{\mathrm{e}}=\mathbf{p}\left(\varphi_{\mathrm{r} \alpha} \mathbf{i}_{\mathrm{r} \beta}-\varphi_{\mathrm{r} \beta} \mathbf{i}_{\mathrm{r} \alpha}\right)
$$

the selection of optimum inverter switching vector, indirect control of stator at standstill. The advantages of DTC are minimal torque response time, absence of coordinate current and voltages, approximately

The DTC control is based on the regulation of the rotor flux magnitude and the value of the torque of the machine. The switching table applied in this work is a standard table. This table makes it possible to define the vector which it is necessary to apply in each sector starting from the exits of hysteresis regulators (rotor flux and torque) and the position of the rotor flux vector. The e vectors $V_{0}$ and $V_{7}$ are alternatively selected so as to minimize the number of commutations in the arms of the rectifier/inverter [8].

TABLE I

Switching table with zero voltage vectors

\begin{tabular}{|c|c|c|c|c|c|c|c|}
\hline$C_{F}$ & $C_{T}$ & $\mathrm{Z}_{1}$ & $\mathrm{Z}_{2}$ & $\mathrm{Z}_{3}$ & $\mathrm{Z}_{4}$ & $\mathrm{Z}_{5}$ & $\mathrm{Z}_{6}$ \\
\hline \multirow{4}{*}{1} & 1 & $\mathrm{~V}_{2}$ & $\mathrm{~V}_{3}$ & $\mathrm{~V}_{4}$ & $\mathrm{~V}_{5}$ & $\mathrm{~V}_{6}$ & $\mathrm{~V}_{1}$ \\
\cline { 2 - 8 } & 0 & $\mathrm{~V}_{7}$ & $\mathrm{~V}_{0}$ & $\mathrm{~V}_{7}$ & $\mathrm{~V}_{0}$ & $\mathrm{~V}_{7}$ & $\mathrm{~V}_{0}$ \\
\cline { 2 - 8 } & -1 & $\mathrm{~V}_{6}$ & $\mathrm{~V}_{1}$ & $\mathrm{~V}_{2}$ & $\mathrm{~V}_{3}$ & $\mathrm{~V}_{4}$ & $\mathrm{~V}_{5}$ \\
\hline \multirow{4}{*}{0} & 1 & $\mathrm{~V}_{3}$ & $\mathrm{~V}_{4}$ & $\mathrm{~V}_{5}$ & $\mathrm{~V}_{6}$ & $\mathrm{~V}_{1}$ & $\mathrm{~V}_{2}$ \\
\cline { 2 - 9 } & 0 & $\mathrm{~V}_{0}$ & $\mathrm{~V}_{7}$ & $\mathrm{~V}_{0}$ & $\mathrm{~V}_{7}$ & $\mathrm{~V}_{0}$ & $\mathrm{~V}_{7}$ \\
\cline { 2 - 9 } & -1 & $\mathrm{~V}_{5}$ & $\mathrm{~V}_{6}$ & $\mathrm{~V}_{1}$ & $\mathrm{~V}_{2}$ & $\mathrm{~V}_{3}$ & $\mathrm{~V}_{4}$ \\
\hline
\end{tabular}

\section{DTC system structure}

The bloc diagram of DTC applied to DFIG is shown in figure. 2 using switching table proposed by Takahashi.

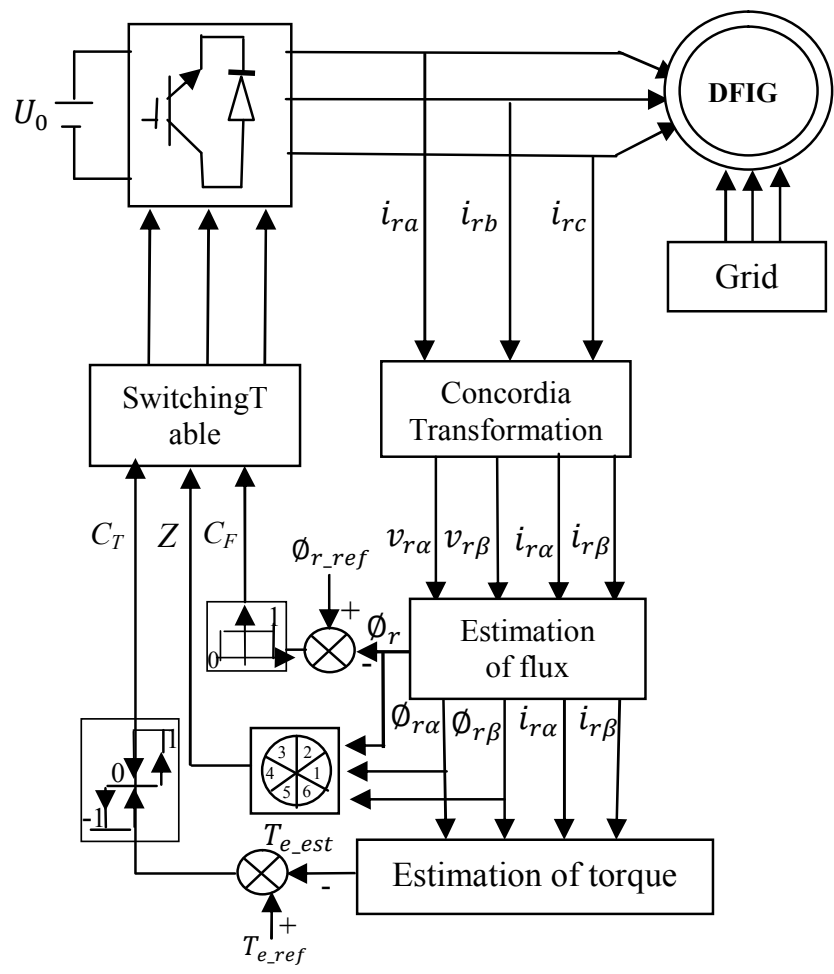

Figure. 2 The diagram of the DFIG direct torque control system. 


\section{Simulation}

Simulation of the proposed direct torque control strategy for DFIG based wind generation system is carriedoutusing MATLAB/Simulink. The parameters of DFIG are given in appendix.

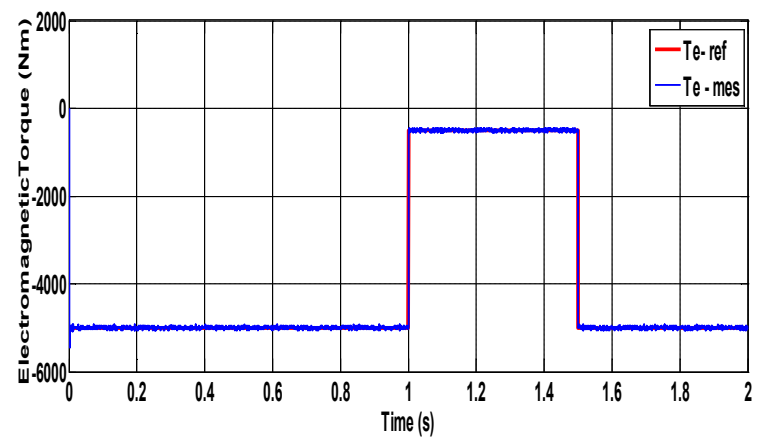

Figure. 3 Electromagnetic torque for 2 step change in reference torque.

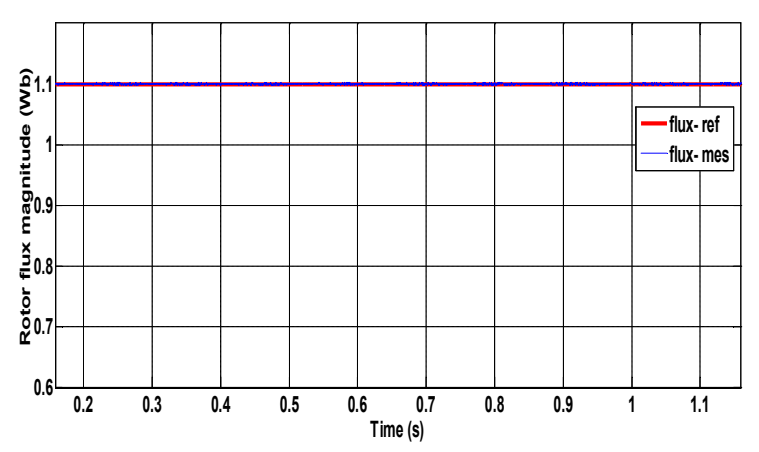

Figure.4 Rotor flux.

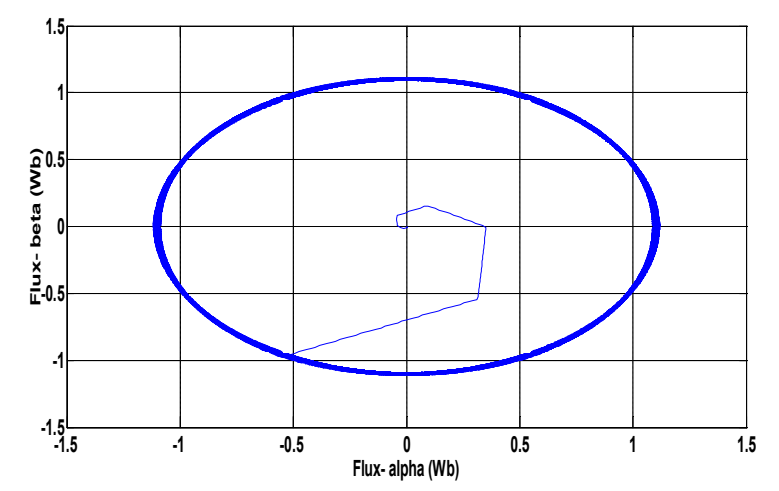

Figure.5 Evolution of rotor flux estimated components

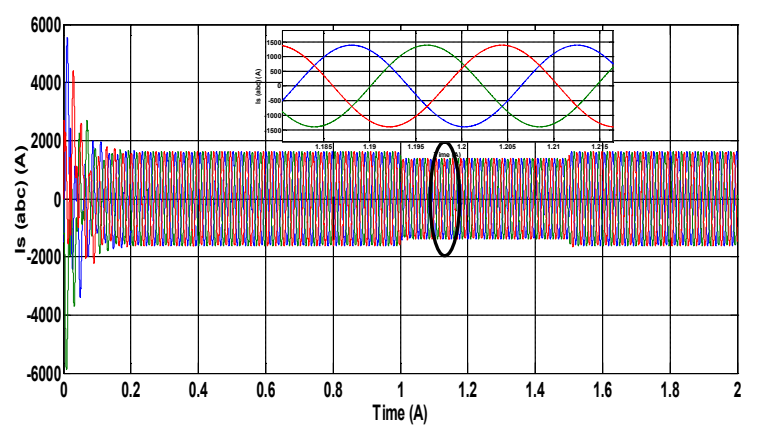

Figure.6 Stator current of DFIG.

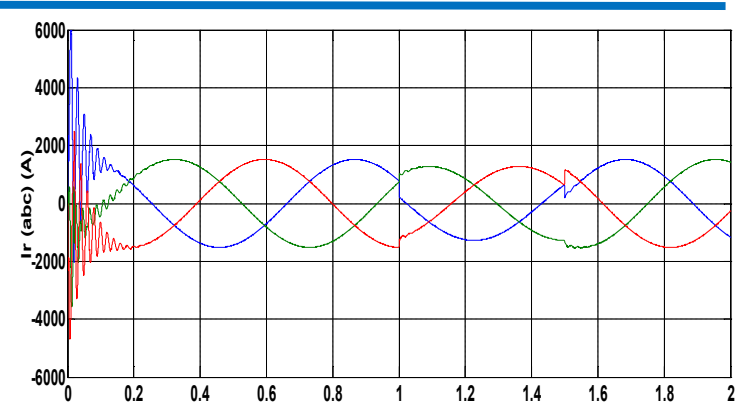

Figure.7 Rotor current of DFIG.

The torque and flux references used in the simulation results are $(-5000$ N.m in $0 \mathrm{~s},-500$ N.min $1 \mathrm{~s}$, and again 5000 N.m in $1.5 \mathrm{~s}$ ) and $1.1 \mathrm{~Wb}$ respectively.. The curves are electromagnetic torque, rotor flux, stator current, and rotor currents.

Figure 3 show that the electromagnetic torque of DFIG is follows the reference value quickly. Figure 4 is showing the rotor flux magnitude response of DTC control strategy. Note that the rotor flux is maintained constant $(1.1 \mathrm{~Wb})$ while torque changes, it certify that the decoupled control of rotor flux and torque is achieved.

Figure 6 show the trajectory of the estimated rotor flux components, the DTC has good dynamic response.

Figure 6 and Figure 7 shows the corresponding stator and rotor currents waveform which are almost sinusoidal with some harmonic in the beginning.

\section{Conclusion}

This paper presents a direct torque control strategy for DFIG based wind energy conversion systems.

Simulation results show that the DTC strategy presents a fast and good dynamic torque in steady state behaviour. However this strategy because of the variable switching frequency presents the drawback to having a high frequency of switching which present a high harmonic distortion of currents, high ripples of electromagnetic torque, and warming-up of the silicon switchers.

\section{Appendix}

TABLE II

Parameters of doubly fed induction generator

\begin{tabular}{|l|l|}
\hline Rated Power $\mathrm{P}_{\mathrm{n}}$ & $1.5 \mathrm{MW}$ \\
\hline Stator Voltage $\mathrm{V}_{\mathrm{s}}$ & $398 / 690 \mathrm{~V}$ \\
\hline Stator Frequency $\mathrm{f}$ & $50 \mathrm{~Hz}$ \\
\hline Stator Resistance $\mathrm{R}_{\mathrm{s}}$ & $0.012 \Omega$ \\
\hline Rotor Resistance $\mathrm{R}_{\mathrm{r}}$ & $0.021 \Omega$ \\
\hline Stator Leackage Inductance $\mathrm{L}_{\mathrm{s}}$ & $0.0137 \mathrm{H}$ \\
\hline Rotor Leakage Inductance $\mathrm{L}_{\mathrm{r}}$ & $0.0136 \mathrm{H}$ \\
\hline Mutual Inductance $\mathrm{M}$ & $0.0135 \mathrm{H}$ \\
\hline Pairs of poles number $\mathrm{P}$ & 2 \\
\hline
\end{tabular}




\section{REFERENCES}

[1] B. B. Pimple, V. Y. Vekhande and B. G. Fernandes, New Direct Torque Control of DFIG under Balanced and Unbalanced Grid Voltage", IEEE Trondheim Power Tech, 2010, pp. 2154-2158.

[2] L. Xu, Senior Member, IEEE, and P. Cartwright, "Direct Active and Reactive Power Control of DFIG for Wind Energy Generation", IEEE Trans. Industrial Electronics, Vol. 21, No. 3, Sep. 2006, pp. 750-758.

[3] Y. Djeriri, A. Meroufel and A. Massoum, "Artificial Neural Network Based Direct Torque Control of Doubly Fed Induction, Journal of Electrical Engineering, JEE, Romania, ISSN 1582-4594, vol.14, No.2, june 2014, pp. 71-79.

[4] S. Belkacem, F. Naceri1, R. Abdessemed, "Reduction of Torque Ripple in DTC for Induction Motor Using InputOutput Feedback Linearization, serbian journal of electrical engineering, Vol. 8, No. 2, May. 2011, pp. 11097.

[5] L R. Zaimeddine and T. Undeland, "Control of a GridConnected Double-FedInduction Generator Wind Turbine", IEEE Trondheim Power Tech, 2011, pp. 1-7.

[6] A. Meroufel, Y. Djeriri, A. Massoum et A. Hammoumi Commande vectorielle par les réseaux de neurones artificiels de l'énergie d'une MADA intégrée à un système éolien", Revue des Energies Renouvelables, Vol. 13 №. 4, Déc 2010, pp. $669-682$.

[7] Y. SreenivasaRao, A. JayaLaxmi, Direct Torque Control of Doubly Fed Induction Generator Based Wind Turbine Under Voltage Dips, International Journal of Advances in Engineering and Technology, IJAET, Vol. 3, No. 2, May. 2012, pp. 711-720.

[8] S. Tamalouzt, T. Rekioua, R. Abdessemed, Direct Torque and Reactive Power Control of Grid Connected Doubly Fed Induction Generator for Variable Wind Speed Turbine", $5^{\text {th }}$ Conference CEE'14 Proceeding, Batna, 2014, pp.16-17. 